\title{
Desdoblamientos de
}

\section{un viaje de Roger \\ Bastide en Brasil*}

Gloria Carneiro do Amaral

$\sqrt{1}$

n 1938, llega a Brasil el profesor francés Roger Bastide, que venía a integrar el claustro de la recién creada Facultad de Filosofía, Letras y Ciencias Humanas de la Universidad de São Paulo. Su trayectoria se revistió de dos aspectos particulares: su larga permanencia en el país — cerca de dieciséis años_ y su sincero aprecio por la cultura brasileña. Desde su llegada, se volcó sobre la lectura de autores brasileños de diversas áreas: sociólogos, folcloristas, novelistas y poetas. Su profundización en la cultura y en la literatura brasileña fue intensa y de resultados rápidos: en 1940, publicó un original estudio sobre Machado de Assis, en el cual, yendo contra la corriente de la crítica nacional, ${ }^{1}$ afirma que el novelista es un escritor tan brasileño que, en sus novelas, el paisaje no es un accesorio, sino que está entrañado en la descripción de los personajes femeninos.

Su contacto con Brasil se dio, en un inicio, a través de lecturas, hasta que, finalmente, Roger Bastide emprendió su primer viaje al noreste, del 19 de enero al 28 de febrero de 1944, realizado con el patrocinio de la revista O Cruzeiro, que lo contrató para una serie de

* Traducción del portugués al español de Fernando Légon.

1 Antonio Cândido, comentando el artículo, llama la atención a la posición de la crítica en aquel momento: «El nacionalismo romántico sobrevivía, por lo tanto, y un gran crítico como Alceu Amoroso Lima, expresando, por cierto, la opinión general, podía decir que Euclides da Cunha era "más brasileño" que Machado de Assis» (1993: 104). 
reportajes sobre la región. Visitó Salvador, Recife y João Pessoa, donde fue recibido por diversas personalidades locales: en Bahía, por el poeta Odorico Tavares, que lo acompañó en las visitas a los candomblés de Salvador, y por Jorge Amado; en Recife, por el director del periódico Diário de Pernambuco, Aníbal Fernandes; en Paraíba, por el representante del gobierno, Ruy Carneiro. Diversos periódicos locales publicaron la visita: Diário de Notícias (el 20 de enero de 1944), O Imparcial y $O$ Estado da Bahia.

El resultado de este recorrido es el libro titulado Images du Nordest mystique en noir et blanc, una mezcla de reportaje, relato lírico y esbozo de estudio sociológico. La propia obra emprendió un sinuoso viaje lingüístico. Como de costumbre, Bastide escribió en francés y el texto fue traducido al portugués para poder publicarse en la revista. El original francés se perdió. En 1978, Charles Beylier, un fraile francés que vivía en Ceará, presentó como tesis académica una traducción de la obra. Comparó textos, estudió el estilo de Bastide y el resultado es una muy exitosa traducción comentada, publicada por Ediciones Pandora. Y es la versión retomada por la Editora Babel en 1995, cuyo texto es utilizado en este artículo.

El interés del viaje queda expresado justo al inicio, cuando Bastide declara no estar interesado ni en el futuro ni en el progreso rápido del noreste, sino en el alma modelada por los ancestrales. Alma ancestral brasileña que, en una obra anterior, $A$ poesia afro-brasileira, había buscado a través de trazos remanecientes en la poesía.

Como punto de partida, se trataba de un viaje de trabajo, pues el profesor se había convertido en periodista, contratado para escribir una serie de reportajes para una revista de amplia divulgación en la época. Se convirtió también en un viaje de investigación, en el que toma los primeros contactos con el mundo del candomblé, cuyo estudio gradualmente lo absorbió y culminó en su tesis de doctorado, Les religions afro-brésiliennes, presentada en 1957 , y su obra más significativa, editada en 1960, con el título de Les religions africaines au Brésil (Contribution à une sociologie des interpénétrations de civilisation). Observaciones como «es una cuestión en la cual se debe hacer una profundización», tras la descripción de algún aspecto del candomblé, revelan su interés por este asunto y su intención de proseguir en su investigación.

Este carácter embrionario de análisis más alentado podía notarse en ocasión de la publicación de los reportajes, pues Fagundes de Menezes, en un artículo en la propia revista $O$ Cruzeiro, le pedía, ya en este momento, una profundización en su visión sobre los candomblés, aunque hubiera apreciado los artículos: «Para quien nació en el noreste, es admirable el poder de observación que demuestra el autor de INM, frente a los candomblés, los changós, el maracatu y el frevo» (Menezes 1945). 
Otro aspecto que se debe recordar de este intelectual polivalente son sus estudios sobre sociología del arte, iniciados en cursos en la Cátedra de Sociología de la USP. El interés estético aparece en observaciones meticulosas sobre el barroco: «Podemos considerar el rococó como una preparación para el romanticismo», "el barroco es un arte subjetivo» (Bastide, 1995: 29-30), y tantas otras. Mostraba incluso un conocimiento profundo sobre el punto en el cual se encontraban los estudios sobre el arte barroco en 1945. Al hablar sobre la libido reprimida en las pinturas de las iglesias de Recife, que se manifiesta, en su opinión, a través de los velos sobre los cuerpos y de los pańos sobre el sexo, afirma que este aspecto de la pintura del siglo Xvi todavía no estaba debidamente estudiado (Bastide, 1995: 174).

El viaje se reviste de un cierto carácter iniciático, si tenemos en cuenta que, en julio de 1951, en un nuevo viaje al noreste, el profesor francés es iniciado en el candomblé, bajo el signo de Changó.

Es también un viaje de construcción de relaciones, pues Roger Bastide entra en contacto con varias personas, cuya relación continuará cultivando. Él mismo llama la atención hacia este último aspecto y hacia el carácter múltiple de su viaje en otros artículos: «Itinerario de la democracia» (Jornal Diário de São Paulo, 1944), articulado alrededor de tres encuentros, con George Bernanos (17 de marzo), Gilberto Freyre (24 de marzo) y Jorge Amado (31 de marzo): «Mi viaje no era sólo un viaje de sociólogo a través del folclor y de las costumbres populares, sino también un viaje ideológico a través de las conversaciones, en el cual cada gran capital constituía como si fuera una etapa en este camino de ideología democrática» (1944, «Encontro com Bernanos).

En el texto sobre Jorge Amado, describe la casa del escritor, la comida saboreada en el almuerzo: «el amor de la buena alimentación es un criterio infalible de civilización» (1944, Encontro com Jorge Amado). La cocinera de Jorge Amado es, por cierto, un personaje destacado en el prólogo de la traducción francesa de Quincas Berro d'Água, como prueba de que las relaciones establecidas en este viaje eran bastante diversificadas.

Y el escritor Jorge Amado confirma este lado de apertura de relaciones particulares, en un texto de jornal de 1944, afirmando que Bastide ha hecho «una legión de amigos» en Bahia e, incluso, «Ochosi es su amigo personal». Resalta también su capacidad de relacionarse con el pueblo, aunque fuera en un portugués proverbialmente precario, afirmando que la gran intimidad que se construyó entre la madrina de candomblé bahiana y el sociólogo francés le parece «un misterio tan grande como el de la Santísima Trinidad». 


\section{El sociólogo en tránsito}

Tmages du Nordeste mystique en noir et blanc se divide en cinco capítulos, cuyos títulos es
útil reproducírselos al lector que tal vez todavía no haya tenido la oportunidad de hojear la obra:

I. Bahía, la mística de las piedras y de la madera esculpida

II. El mundo de los candomblés

III. Tres divinidades: Echu (Eleguá), Ochalá (Obatalá) y Yemayá

IV. Las iglesias de Recife, salas de visita de los dioses

V. 1. Changós y Maracatus

2. El encuentro del negro y del indio

Conclusión. Una civilización de ritmos

Se puede percibir así, con claridad, que el libro se articula alrededor de dos polos: el barroco y el candomblé.

El sociólogo se hace presente a lo largo del texto y más específicamente en el gran tema de la obra de Bastide, las religiones afrobrasileñas; esto es, en los capítulos II, III y V.

Para un lector no brasileño, probablemente no tan familiarizado con la obra de nuestro autor, algunas palabras sobre las religiones africanas tal vez sean bienvenidas. Los capítulos dedicados al asunto esbozan un análisis de la estructura festiva y social del candomblé, de las diferencias entre el cristianismo y el candomblé, de la oposición entre la mística cristiana y la africana. Señalan algunos puntos distintivos de la mística africana como los dioses ambivalentes; el nacimiento y la muerte por etapas; el poder de los orishas sobre los devotos. Se levantan aspectos históricos y económicos como la sustitución de la seda por el algodón en las vestimentas usadas en las fiestas. Una mirada que ya está volcada hacia los fenómenos del sincretismo.

Se siente su gran interés por el fenómeno del trance, que le parece ser visto como locura, por ser estudiado por hombres de la medicina. Bastide lo considera una crisis mística que lejos de ser casual se despierta, en realidad, dentro de reglas precisas del culto y cuya explicación debe ser sociológica. Quisiera resaltar una vez más que estas observaciones son un punto de partida para su estudio más amplio y también que Bastide ya había leído, en ese momento, de forma sólida, estudiosos brasileños del candomblé como Nina Rodriguez, Arthur Ramos, Manuel Quirino y Edison Carneiro. En resumen, se percibe la fascinación del investigador ante todo ese material inédito para él. 
El sociólogo, aliado al crítico de arte, aparece también al tratar el barroco: «Para comprender bien el barroco de Bahia, es necesario evocar la antigua sociedad colonial» (Bastide, 1995: 23), lo cual quiere decir que, para entender el barroco, debemos conocer la sociedad de la caña de azúcar. Y para ello, el sociólogo francés ya tenía los ojos bien abiertos, pues una de sus primeras lecturas sobre Brasil fue Casa-Grande e Senzala².

Y un sociólogo de observaciones sagaces e ingeniosas: la iglesia baiana es una iglesia de sacristía, que funciona como espacio social de una sociedad rural, horizontal: «tanto un salón como una capilla» (Bastide, 1995: 24) y la iglesia minera es una iglesia de cofradías, de una sociedad urbana de luchas de clases.

Su sociología parte, muchas veces, de la observación de pequeñas escenas cotidianas: «No me sorprende que las damas de mantillas negras, que venían a murmurar sus oraciones, no hayan encontrado aquí otra satisfacción que la de un nuevo patriarcado, que continuaba siendo el de la casa grande y les enseñaba la humildad y la sumisión» (Bastide, 1995: 34). Las mujeres de mantilla en la iglesia le desvendan la estructura de la sociedad.

Se trata de un sociólogo que se apoya, con frecuencia, en elementos inesperados: «la filosofía está en las piedras no en los libros» (Bastide, 1995: 26). Sus conclusiones parten, en su propio lenguaje, de escuchar la voz que viene de las piedras: «No es necesario, por tanto, describir todas las iglesias de Bahía, es suficiente permanecer en una de ellas y escuchar la voz que viene de sus piedras talladas, de sus maderas esculpidas y doradas» (Bastide, 1995: 32). Un comportamiento próximo al poeta que le parece fundamental para la comprensión de esa sociedad tan diferente de su medio de origen.

Todo se puede transformar en elemento de lectura o fuente de observación sociológica. Un ejemplo significativo se encuentra en un texto de 1931, publicado en Revue Internationale de Sociologie, "Les Arméniens de Valence», en el cual Bastide afirma ser muy fácil distinguir la vivienda de un francés y de un armenio: en el jardín del primero, flores; en el del segundo, transformado en espacio de utilidad práctica, plantas y hierbas. En un caso, la voz de la piedra tallada; en el otro, la de las plantas. Una sociología — si me es permitido decirlo- lírica.

La observación del sociólogo se hace de una forma libre, asumida explícitamente: «Permítanme hacer algunos rodeos en el camino, tomarme mi tiempo. No conozco, en

2 Obra conocida de Gilberto Freyre, por la cual Bastide conservó un gran aprecio, llegando a traducirla al francés con el título de Maîtres et esclaves. Hasta el presente es todavía, con flagrantes equívocos, la traducción a través de la cual los franceses entran en contacto con esta importante obra sobre Brasil. 
efecto, ningún espectáculo más encantador que el del candomblé preparándose para la fiesta. Me gustaba pasear entre ellos, siguiendo la avenida Vasco da Gama, que une los terreiros en una línea continua de verde. Me parecía estar en plena África» (Bastide, 1995: 90)

El viaje se cruza con la observación sociológica, incorpora un lado de turista, sin que ello deba ser entendido de forma peyorativa o reductora, y le confiere a la sociología de Roger Bastide un côté flâneur, de rêverie.

$\mathrm{Y}$, ante este material de estudios, del cual resalta igualmente su carácter místico y su posición de observador, no está exento de participación: "Quedamos entregados sin defensa a la más terrible de las aventuras» (Bastide, 1995: 33). Esta mezcla de niveles, esta ambigüedad es la que le permite la gran perspectiva angular de observaciones que integran vida, sociología y arte: «El barroco no es simplemente una forma de arte. Es también un estilo de vida» (Bastide, 1995: 38).

Y, por último, el libro hace referencia a un asunto hoy muy estudiado por la sociología, pero que en la época todavía era de interés periférico: los carnavales. Aunque lo fascinaban, no deja de lado una observación más consistente. Observa en Recife un carnaval individual y otro colectivo. Y también que los bailarines de frevo, en general, están constituidos por blancos y los bloques o comparsas, por negros, que conservan la organización tribal africana manifestándose de forma más gregaria y exhiben disfraces o fantasías más suntuosas.

\section{Una escritura poética}

En este libro de viajes y de estudio, el estilo es el de una narrativa de viaje, entrelazada a la observación científica y en lenguaje poético. ${ }^{3}$

El propio autor muestra una vuelta a la postura crítica en la introducción: «No es más que un conjunto de imágenes. No se trata de un libro de ciencia pura, menos todavía de una especie de canto lírico». Señala como defecto principal del trabajo «una vacilación entre la ciencia y la poesía»; lo cual, desde otra perspectiva, puede ser considerado una cualidad. Él mismo, después de vivir más tiempo en Brasil, en la introducción a Brasil, terra

\footnotetext{
${ }^{3}$ Otras narrativas que presentan esa mezcla son producidas por intelectuales de esa generación. Otro francés que circuló por Brasil y que fue profesor de la misma facultad (para cuya plaza fue contratado Roger Bastide) Lévi-Strauss, en una obra que se volvió mucho más conocida, Tristes trópicos, se muestra preocupado con la diversidad de facetas exigidas a un intelectual en este momento.
} 
de contrastes, de 1959, rescatará la observación poética del medio ambiente: «El sociólogo que quiera comprender a Brasil no pocas veces debe convertirse en poeta».

Su rigor intelectual hace que juzgue su trabajo sin ninguna indulgencia. Teniéndose en cuenta que el punto de partida es, como él mismo afirma en el prólogo, «un simple reportaje literario», al cual le ha mezclado su alma de sociólogo, el resultado es envolvente e interesante desde varios aspectos. En realidad, una de las riquezas de la obra es esa ambigüedad, traducida principalmente en el lenguaje.

Estamos ante un texto ágil, múltiple, con momentos de gran lirismo y de pura literatura, al lado de descripciones objetivas de las ceremonias y de aspectos relacionados al candomblé. Se debe considerar aquí que la variedad y la no ortodoxia son características esenciales del trabajo intelectual de Roger Bastide, que consigue equilibrar con rigor científico, apertura de perspectiva y ningún convencionalismo.

El lenguaje poético que integra el espíritu de la obra se manifiesta principalmente en las descripciones.

Al hablar de los candomblés, en plena observación de campo, el poeta se inmiscuye en la descripción de las danzas: «Danza lenta, lánguida, adaptada a la dulzura del crepúsculo, a la ternura de las primeras estrellas que se abren como flores de plata en el cielo del atardecer; música monótona, repitiendo incansablemente las mismas palabras: Boi obota» (Bastide, 1995: 94).

O al describir los santuarios de los candomblés, en el capítulo II. Aquí el sociólogo y el poeta tienen funciones definidas. Cuando se trata de describir el interior de los santuarios, lo cual implica informaciones sobre el funcionamiento religioso y sobre los ceremoniales, la descripción es objetiva y parca en adjetivos. Consta incluso en la obra un mapa del santuario (Bastide, 1995: 79). Sin embargo, la descripción del exterior y de la naturaleza tropical está en un lenguaje poético de un enunciador europeo maravillado con el paisaje circundante:

«Los santuarios se esconden entre el verde: las hojas de palmas y plátanos los cubren y les sirven de adorno; son verdaderos jardines místicos, donde se entra por senderos en el monte, atravesando arroyos murmurantes, pasando por plantaciones de maíz y bosques floridos. Cuando pasamos, los árboles dejan caer sobre nosotros la pulpa suculenta y perfumada de sus frutos maduros que al caer se aplastan haciendo un ruido dulce y azucarado» (Bastide, 1995: 72).

Los dos capítulos en los cuales el lirismo y el lenguaje poético se hacen presentes de forma más intensa son exactamente los capítulos de las descripciones de los espacios (de las 
ciudades de Salvador y de Recife y de sus iglesias) vinculados directamente al enunciador viajero, salidos del tema del viaje.

Abro aquí un paréntesis indispensable. Roger Bastide nunca escribió un texto exclusivamente dedicado a Baudelaire. Aunque en su primer artículo de 1922, «Hipocresía visual en la poesía contemporánea», elija dos versos de "Correspondencias» como ejemplo de comparación:

Hay perfumes frescos como la carne de los niños

Dulces como oboes, verdes como las praderas.

Otro texto, «Interpretación de Baudelaire» (1947) es una reseña sobre el libro homónimo de Pierre-Jean Jouve y no un estudio directamente sobre el primer poeta. Por otro lado, tiene dos estudios (de 1932 y 1934) sobre Jouve, poeta que, además de escribir sobre Baudelaire, presenta acentuados trazos baudelairianos en su poesía. Y, en uno de sus ensayos sobre Cruz e Sousa, Bastide compara al poeta brasileño con el poeta francés.

Todo ello indica que el sociólogo leía al poeta de Flores del Mal, lo cual, por cierto, no le confiere ninguna originalidad. Pero tal vez se pueda decir que el espectro de Baudelaire ronda con frecuencia el alma de Bastide, convirtiéndose en una especie de espíritu fantasma que se le encarna, especialmente intenso en Images du Nordeste mystique en noir et blanc.

El libro se abre con una descripción del puerto de Salvador: barcos y velas se mecen «débilmente», en una pereza tropical que contagia a los marineros, entorpecidos por el calor y cuyos corazones nostálgicos están llenos de recuerdos de viajes. Una situación análoga a la de «Parfum exotique», estamos en un mismo puerto delante de veleros, cuyos mástiles evocan selvas tropicales. Los dos observadores europeos se deslumbran con el calor y con la sensualidad de los trópicos.

Alejándose del puerto, el narrador entra en la iglesia de Nuestra Señora. Virgen de la Playa, que es para él la iglesia de las "correspondencias secretas y analógicas», evocando a Lisboa, de donde vinieron los bloques de mármol que la componen y explicando las «correspondencias» entre Portugal y Brasil.

Ecos del soneto «Correspondencias», en que "La naturaleza es un templo en que pilares vivos/dejan a veces salir palabras confusas» y el hombre atraviesa «selvas de símbolos» puntúan la descripción de las iglesias de Recife; el enunciador establece la misma relación de la forma de los troncos con las columnas de la iglesia: «Y a la noche, en el momento en 
que el rojo de los campos se extingue en la sombra, cuando los troncos de los cocoteros ya han transformado la selva en una catedral nocturna, con sus columnas vegetales cubiertas por un techo de palmas, los mocambos encienden sus lámparas, como estrellas terrestres» (Bastide, 1995: 173).

El tropicalismo del paisaje es un aspecto constante en la descripción del espacio geográfico. Recife es «la Venecia de los trópicos», donde el hombre dominó el mar y el pantano.

«Pero los ojos de las mujeres, incluso los de las mulatas color canela, conservan - por haber contemplado durante siglos este paisaje de agua dulce y estancada - sus reflejos verdes; reflejos matizados que evocan, bajo sus espesas pestańas, bajo el parpadeo de sus ojos, estanques misteriosos, pozos claros o torbellinos con las cuerdas de su guitarra. Los ojos de las mujeres se conservan como Venecias tropicales» ${ }^{4}$ (Bastide, 1995: 160).

Y, aludiendo a la mirada femenina como metonimia del paisaje, podemos acordarnos del referido ensayo literario de Roger Bastide sobre Machado de Assis, en el cual defiende la presencia del paisaje, no de forma exótica, pintoresca y externa, sino interiorizada, integrada a la descripción de la mujer, creando «mujeres-vegetales», «mujeres-paisajes», en su andar, en sus cabelleras: «Las noches de Río se vuelven cabelleras, cabellos sueltos, perfumados, tibios, voluptuosos». Así, andar, mirada y cabellera son metonimias baudelairianas corrientes en el ciclo Jeanne Duval, en el que la figura femenina se proyecta también contra un paisaje tropical. $^{5}$

Como balance final hemos de convenir que todas estas observaciones partiendo de un francés de la primera mitad del siglo xx y con unos cinco años en Brasil deben despertar nuestra atención. Me parecen principalmente que son consecuencia de la manera con la que Roger Bastide observaba al otro, sin intentar llenar expectativas de una visión pintoresca, sino, al contrario, observando diferencias en la esencia de lo real, procurando entender una realidad circundante bastante diferente de aquella de la cual él mismo se originaba. Un observador literalmente desprovisto de prejuicios.

\footnotetext{
4 Una mujer paisaje aparece en otros poemas de «Spleen et idéal». «Cielo neblinosos (Ciel brouillé)»

5 Tu mirar misterioso. (¿Es azul, gris o verde?) / Alternativamente tierno, cruel, soñador, / refleja la indolencia y la palidez del cielo. // As veces te asemejas a esos bellos paisajes, / que iluminan los soles de estaciones brumosas... / ¡Y cómo resplandeces, oh mojado paisaje, / que atraviesan los rayos entre un cendal de niebla! // ¡Oh, mujer peligrosa, oh, seductores climas! (Trad. Versiones de Antonio Martinez Carrión. La Gaya Ciencia S.A. Barcelona, 1976).
} 


\section{BIBLIOGRAFÍA}

Candido, Antonio

1993 «Machado de Assis de outro modo». En Recortes. São Paulo: Companhia das Letras.

BASTIDE, Roger

1931 «Les Arméniens de Valence». Revue Internationale de Sociologie, N. ${ }^{2}$ 1-2 pp. 17-42.

1940 «Machado de Assis, paisagista». Revista Brasileira, N. o 25, noviembre, pp. 1-14.

1943 A poesia afro-brasileira. São Paulo: Livraria Martins Editora.

1944 «Encontro com Bernanos». Diário de São Paulo, 17 de marzo.

1944 «Encontro com Jorge Amado». Diário de São Paulo, 24 de marzo.

1944 «Encontro com Gilberto Freyre». Diário de São Paulo, 31 de marzo.

1995 [1945] Images du Nordeste mystique en noir et blanc. París: Actes Sud/Babel.

Menezes, Fagundes de

1945 «O professor Bastide e o Nordeste místico». O Cruzeiro, 29 de octubre. Río de Janeiro. 